\title{
First observation of aromatic bond density: a 'forgotten' paper by Rosalind E. Franklin \\ A Nazarenko ${ }^{1}$ \\ ${ }^{1}$ Chemistry Dept, SUNY Buffalo State \\ nazareay@buffalostate.edu
}

In 1949 Rosalind Franklin wrote a paper [1] on the influence of the bonding electrons on the scattering of X-rays by graphite which was published in Nature in January 1950. In this paper, it was unambiguously shown that for quantitative description of X-ray scattering, it is necessary to consider electrons located between two carbon atoms: independent atom model fails. These observations were confirmed much later [2] by more accurate experimental studies. Arguably, the paper in Nature was the first correct observation of covalent bond density. Indeed, earlier work by Bragg [3] and Ewald [4] on diamond crystals was explained later by Renninger [5] as a result (at least in part) of multiple diffraction, now known as the Renninger effect. The object of study was also irreplaceable. Covalent bond electron density in graphite is almost twice higher than in diamond, making deformation electron density much more visible. Covalent crystals of elements other than carbon do not exhibit such prominent effects as graphite: silicon, for example, has a much lower Coppens' suitability index. In 1949, it was impossible to observe deformation density in organic molecular crystals. Quantitative description of diamond was done much later [6] using essentially the same approach as in Franklin's paper. The systematic studies of the deformation density have been started much later, by the end of the 1960s. Nevertheless, there is no reference to paper [1] in any of the works on multipole model or, more recently, quantum crystallography. However, the idea of keeping the conventional IAM model but supplement it by small isotropic interatomic scattering centers, at the positions located between atoms and at lone pairs' locations, was employed in several models [7]. This approach is especially successful for aromatic organic molecules, which, of course, exhibit similarity to graphite bonding. It seems that appropriate recognition of Rosalind E. Franklin's impact on charge density research is long overdue.

[1] Franklin, R. E. (1950). Nature, 165, 71-72.

[2] Moss G. (1978). Acta Cryst. A34, 91-94

[3] Bragg WH. (1920). Proc. Phys. Sci. London. 33, 304-311

[4] Ewald P. P. \& Hönl H. (1936a) 417, 281-308; Ewald P. P. \& Hönl H. (1936b) 418, 673-696.

[5] Renninger, M. (1937). Z. Phys. 106, 141-176

[6] Brill R. (1960) Acta Cryst. 13, 275-276.

[7] Afonine, P.V et al.( 2007). Acta Cryst. D63, 1194-1197; Dadda, N. et al.. (2012). A68, 452-463; Nazarenko, A.Y. (2018). Z. Krist.,38, S44-S45 